\title{
A STUDY OF THE REACTIONS BETWEEN TUNGSTEN DIOXIDE
}

AND DIFLUORODICHLOROMETHANE

by

A. Dinsmoor Webb

Herbert A. Young

\section{University of California \\ Radiation Laboratory}

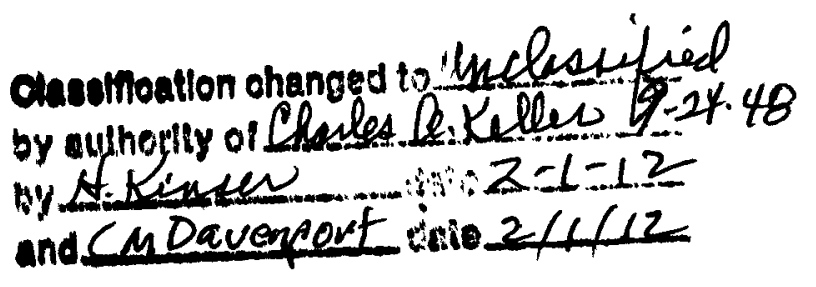

Date of Manuscript, July 15, 1948

Date Declassified: September 24, 1948

This document is for official use.

Its issuance does not constitute authority for declassification of classified copies of the same or similar content and title and by the same authors.

Technical Information Division, Oak Ridge Operations AEC, Oak Ridge, Tenn., 1-19-49--750-A445

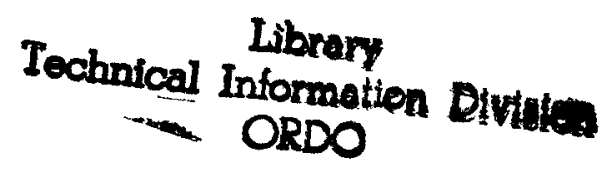




\section{DISCLAIMER}

This report was prepared as an account of work sponsored by an agency of the United States Government. Neither the United States Government nor any agency Thereof, nor any of their employees, makes any warranty, express or implied, or assumes any legal liability or responsibility for the accuracy, completeness, or usefulness of any information, apparatus, product, or process disclosed, or represents that its use would not infringe privately owned rights. Reference herein to any specific commercial product, process, or service by trade name, trademark, manufacturer, or otherwise does not necessarily constitute or imply its endorsement, recommendation, or favoring by the United States Government or any agency thereof. The views and opinions of authors expressed herein do not necessarily state or reflect those of the United States Government or any agency thereof. 


\section{DISCLAIMER}

Portions of this document may be illegible in electronic image products. Images are produced from the best available original document. 


\section{A STUDY OF THE REACTIONS BETWEEN TUNGSTEN DIOXIDE}

\section{AND DIFL UORODICHLOROMETHANE}

By A. Dinsmoor Webb and Herbert A. Young

\section{ABSTRACT}

It has been known for several years that carbon tetrachloride could be used as a chlorinating agent for several of the heavy metal oxides.' It has lately been reported also that some of the simple freon type compounds yield uranlum tetrafluoride when passed over heated uranium trioxide. ${ }^{2}$ This paper will report the substances obtained by reaction of difluorodichloromethane with tungsten dioxide at temperatures near $525^{\circ} \mathrm{C}$.

Initial investigations in pyrex glass equipment established the fact that there was a reaction between the $\mathrm{CF}_{2} \mathrm{Cl}_{2}$ gas and the pyrex glass at temperatures of $500^{\circ} \mathrm{C}$ and higher. Substitution of a small nickel metal tube for glass permitted establishment of the facts that all of the turgsten containing products of the reaction between $\mathrm{CF}_{2} \mathrm{Cl}_{2}$ and $\mathrm{WO}_{2}$ were volatile at $500^{\circ} \mathrm{C}$. It was found also that there was considerable variabllity in the products that solidified on a cold finger projecting into the reactor with variations in the temperature of the reaction and with variations in the rate of introduction of $\mathrm{CF}_{2} \mathrm{Cl}_{2}$ gas to the reactor. Table 1 presents some typical results of cold finger product analyses. Although the reaction between $\mathrm{CF}_{2} \mathrm{Cl}_{2}$ and $\mathrm{WO}_{2}$ was found to go at temperatures as low as $400^{\circ} \mathrm{C}$, it was slow at $500^{\circ} \mathrm{C}$. The intermediate temperature; $525^{\circ} \mathrm{C}$, was therefore chosen as the optimum for this work. It has been shown that pure nickel and monel metal are the two metals most resistant to attack by fliorine because of the formation on their surfaces of protective nickel fluoride films:

In view of the complex nature of the mixture condensed on the cold finger in the preliminary type reactor, it was decided to construct a reactor designed so that fractionation of the reaction products according to their solidification temperatures would be obtained. The resistance of nickel to attack by fluorine indicated that the reactor should be constructed of that metal, while the small amounts of sample obtained by operation at $450^{\circ} \mathrm{C}$ suggested the use of higher temperatures. It was found that silver solder cotild resist the action of freon at $450^{\circ} \mathrm{C}$ fairly well, but that at $500^{\circ} \mathrm{C}$ it reacted rapidly so the new reactor had to be nickel welded in all of its seams.

\section{EXPERIMENTAL APPARATUS}

The reaction tube in its final forth was made from a 3 -foot long piece of pure nickel pipe 2 inches in diameter. Flanges with removable cover plates of hickel were welded to each end of the length of pipe. The nickel tube was heated by an electrical resistance furtiace over 18 inches of its length. The temperature within the heated portion of the tube was regulated by a system consisting of a variable transformer and a potentlometer type on-off controller. The regulating thermocouple was inounted within a nickel thermowell at a point in the center of the tube radially and 8 inches inside the furnace. The charges of tungsten dioxide were carried in a structural carbon boat which fitted inside a piece of lighter wall nickel tube 16 inches long.

Structural carbon was chosen as sample carrier because it was completely unreactive with the

$$
\text { AECD - } 2315
$$


Table 1.

\begin{tabular}{|c|c|c|c|c|c|}
\hline Run No. & $\begin{array}{l}\text { Temp. } \\
{ }^{\circ} \mathrm{C}\end{array}$ & $\begin{array}{l}\text { Freon charge rate } \\
\text { pressure drop at } \\
\text { orifice, inches } \mathrm{H}_{2} \mathrm{SO}_{4}\end{array}$ & $\begin{array}{l}\text { Produ } \\
\text { W } \\
\text { wt. } \%\end{array}$ & $\begin{array}{l}\text { on col } \\
\text { wt. } \%\end{array}$ & $\begin{array}{c}\text { finger } \\
\text { Cl } \\
\text { wt. } \%\end{array}$ \\
\hline CF 2 & 600 & 0.2 & 52.2 & - & - \\
\hline CF 3 & 500 & 0.2 & 65.0 & 7.2 & 4.7 \\
\hline CF 4 & 450 & 0.2 & 60.4 & 3.7 & 16.9 \\
\hline CF 7 & 450 & 0.2 & 78.0 & 15.1 & 12.7 \\
\hline CF 9 & 450 & 1.7 & 65.7 & 7.8 & 6.7 \\
\hline CF 10 & 450 & 1.7 & 67.9 & 6.5 & 2.8 \\
\hline CF 11 & 450 & 1.4 & 65.2 & 8.0 & 8.6 \\
\hline CF 12 & 450 & 1.3 & 59.7 & 6.1 & 13.7 \\
\hline
\end{tabular}

freon and $\mathrm{WO}_{2}$ at $525^{\circ} \mathrm{C}$. It was found, for instance, that small amounts of $\mathrm{NiF}_{2}$ contaminant got into the carbon produced by the reaction when a nickel boat was used, thus making accurate determinations of carbon produced and $\mathrm{WO}_{2}$ unreacted more difficult. The light wall tubing carrying the carbon boat fitted into the longer nickel tube so that the sample of tungsten dioxide was placed just below the regulating thermocouple. The reacting gas, difluorodichloromethane, was introduced into reactor through a piece of $1 / 8$ inch nickel pipe through the zone in which heat from the reactor was present. The gas inlet pipe penetrated the cover plate through which the thermowell was mounted at the hotter end of the large nickel tube. The remaining space within the flange nickel reactor tube was filled with specially designed segments of nickel pipe, each containing baffles which served to collect the products which sublimed from the high temperature zone.

The collector segments, made from nickel tubing in order that they be fluorine resistant, were of the same diameter and wall thickness as the piece of tubing that carried the carbon boat in the reaction zone. The three baffles in each collector segment were arranged so that half of the circular area was closed at each end of a segment, while in the middle of each segment three-quarters of the area was blocked. The closed portion of the area of the center baffle was on the same side as the open portions of the two end baffles. By this arrangement of baffles, the gas stream impinged upon three surfaces in each collector segment.

Since it was not known how many solid phases would be present in the material collected on one segment, it was not possible to calculate the theoretical requirements of a fractionating apparatus. However, because of the non-fluid nature of the solid-gas system the results from design with either the single phase solid solution system or the poly-phase solid mixture under consideration are what are embodied in the collector units used in this work. Consideration of the material solidifying on the hottest surface in the temperature gradient section of the reactor presents two alternatives:

(1) If the crystals are a single phase solid solution then the gas phase in equilibrium with it will very probably be richer in the component of higher vapor pressure. By analogy to the liquidvapor system we should expect then that there should be a small amount of resublimation. Since there is no method by which the solid phases remaining on the collector segments can be returned to higher temperature zones, we should want a large number of surfaces of successively lower temperature to project into the vapor stream to permit as many opportunities for the transition from vapor to solid and consequent partial resublimation as possible.

(2) In case the solid which condenses on the hottest collector segment is polyphase, with 
differing phases relatively pure, we should expect the composition of vapor in equilibrium with the solid to be independent of the solid composition, and to depend rather upon the vapor pressures of the two phases at that temperature. Thus there could be no separation of phases of differing vapor pressures after condensation. The reason for using a series of metal baffles of successively lower temperatures in this latter case would be to condense different solids which could result from differences in the course of the reaction as the surface of the reacting $\mathrm{WO}_{2}$ was covered by the carbon produced. Since the materials which solidified on the collector units in this work seemed to be homogeneous, it is likely that the discussions pertaining to the single phase solid solution system are the ones applying in the separation of $\mathrm{WOCl}_{4}, \mathrm{WCl}_{6}, \mathrm{WOF}_{4}$ mixtures.

The collector segments were constructed so that when they were assembled in the reactor tube there was a fairly snug fit between the boat carrying tube and the first collector segment, and also between each pair of segments throughout the length of the reactor tube. A total of twelve collector segments was used, the first one being just within the furnace at a temperature of $525^{\circ} \mathrm{C}$ while the last segment was located within the portion of the furnace tube which was cooled with water at $0^{\circ} \mathrm{C}$. The furnace tube between these two temperature sections was wrapped with asbestos cloth to help in maintaining an even temperature gradient. The average temperature gradient was $44^{\circ} \mathrm{C}$ between collector segment centers. The gas velocity through the reactor in all experiments in which fractionation of products was desired was maintained at a rate of not over $10 \mathrm{ml}$ per minute.

The equipment as designed and operated, while providing for no reflux, served satisfactorily to partially fractionate materials of sublimation temperatures as close as $40^{\circ} \mathrm{C}$. A reactor that could obtain the effect of reflux in a solid-gas system could be built by using a much longer tube filled with collector segments, and providing for gradually moving a furnace dow $n$ the length of the tube so that the temperature gradient zone would pass slowly over several collector segments. A reactor of this design was not tried, as enough fractionation was obtained in the single stage system to permit identification of the substances in the mixture.

To prevent reaction of the sublimed materials with the water vapor of the atmosphere, the cooler end of the furnace tube projected into a large box in which an atmosphere of extremely dry nitrogen was maintained. The gas in the dry box was circulated through a laboratory model "Lectrodryer" by means of a small centrifugal blower. The product materials were transferred from the collector segments to tared weighing bottles inside the dry box. The operators hands and arms were protected by thin rubber gloves, and to assure that no moist air entered the box through the arm ports, dried nitrogen was introduced into the box at a high rate during the sample transferring period.

\section{Analytical Procedures}

It was found necessary to start the analysis of the material collected within a short time of collection, as decomposition was evidenced by the presence of chlorine gas over the solid sample in a weighing bottle within a few days of the collection of the sample. In other samples which were held in weighing bottles for several days, etching of the glass was observed. In view of the instability of the materials collected, the samples were weighed and dissolved in cold dilute $\mathrm{NaOH}$ solutions within an hour of their collection. In nearly all cases the entire sample was found to be soluble in cold dilute $\mathrm{NaOH}$ solution, the first almost instantaneous reaction giving a clear solution and a precipitate of yellow $\mathrm{WO}_{3}$ which then dissolved with shaking in 15 to 20 minutes. Insoluble portions, present in amounts of the order of 1 percent or less, were filtered out, and the clear solutions were analyzed for tungsten, fluorine, and chlorine. The difference between the total sample weight and the sum of the tungsten, fluorine, and chlorine found was calculated to be oxygen.

The tungsten present in the sample, after dissolving in $\mathrm{NaOH}$ solution was in the form of tungstate ion. Since a soluble complex was formed between $\mathrm{WO}_{3}$ and $\mathrm{F}^{-}$, it was necessary to remove the $F^{-}$from the solution. This was done by evaporating the solution to dryness twice after the addition of generous portions of concentrated $\mathrm{HCl}$ solution. Evaporations were done under infrared lamps to 
prevent spattering. The residue from the second evaporation was taken up in $2.5 \mathrm{~N} H \mathrm{Hl}$ solution, a solution of brucine hydrochloride was added and the precipitated $\mathrm{WO}_{3}$ was allowed to settle overnight before filtration on quantitative paper. ${ }^{4}$ The paper was burned off at about $400^{\circ} \mathrm{C}$ and the $\mathrm{WO}_{3}$ was finally ignited to $700^{\circ} \mathrm{C}$ for 30 minutes in an electric muffle furnace. Small platinum crucibles were used so that the $\mathrm{WO}_{3}$, after weighing, could be treated with $\mathrm{HF}$ solution and a few drops of concentrated $\mathrm{H}_{2} \mathrm{SO}_{4}$ to remove any $\mathrm{SiO}_{2}$ present. Finally, the $\mathrm{WO}_{3}$ residue was converted to soluble sodium tungstate by fusion with solid $\mathrm{Na}_{2} \mathrm{CO}_{3}$. Any residue insoluble after the carbonate fusion would be nickel oxide which would have come from the reactor tube or collector segments. Duplicate analyses of $25 \mathrm{ml}$ aliquots from one unknown solution showed that the tungsten analysis was precise since $.0549 \mathrm{~g}$ of $\mathrm{WO}_{3}$ was obtained in each of the analyses. A determination of the accuracy of the tungsten analytical method showed $99.58 \%$ recovery on a sample which contained $.0^{\prime} 23 \mathrm{~g}$ of $\mathrm{WO}_{3}$.

The fluorine and chlorine present in the sample were determined by analysis of a second aliquot from the clear $\mathrm{NaOH}$ solution of the original sample. The fluoride ion in a $10 \mathrm{ml}$ aliquot was steam distilled as $\mathrm{H}_{2} \mathrm{SiF}_{6}$ from $15 \mathrm{ml}$ of concentrated $\mathrm{HClO}_{4}$ containing some small pieces of soft glass rod, under carefully controlled conditions of temperature and rate of steam introduction. 5 The chloride ion distills at the same time as $\mathrm{HCl}$. Two methods were used to estimate the $\mathrm{H}_{2} \mathrm{SiF}_{6}$ and $\mathrm{Cl}^{-}$in the distillate from the concentrated $\mathrm{HClO}_{4}$. In the first procedure, the entire quantity of distillate was titrated with $\mathrm{Th}^{4+}$ to the pink end point of the Th-alizarin lake. The end point was found to be sharp and reliable when the solution was suffered at pH 3.1 with half-neutralized chloracetic acid. The $\mathrm{Cl}^{-}$ was determined with the same solution after filtering out the precipitated thorium fluoride, by titration turbidimetrically with slightly acid mercuric nitrate solution to the mercuric nitroprusside end point. It was found that the chloracetic acid bufjer decomposed to give $\mathrm{Cl}^{-}$however, so that a second procedure was developed in which this decomposition would not interfere.

Two hundred milliliters of steam distillate from the concentrated $\mathrm{HClO}_{4}$ solution was thoroughly mixed and divided into two equal portions. One portion was titrated with the standard mercuric ion solution after making it approximately one normal in $\mathrm{H}^{+}$by the addition of dilute $\mathrm{HClO}_{4}$ solution. It was found that there was no interference by the $\mathrm{SiF}_{6}^{--}$in acid solution. In fact, it was found that $\mathrm{Cl}^{-}$ in the presence of $\mathrm{F}^{-}$could be titrated if the $\mathrm{H}^{+}$were increased to approximately one normal, probably because of the weakness of HF. The second portion of the distillate was titrated with standard $\mathrm{Th}^{4+}$ solution after the addition of alizarin indicator and buffering at $\mathrm{pH} 3.1$.

The analytical procedures were standardized by making solutions of varying concentrations of $\mathrm{WO}_{4}{ }^{--}, \mathrm{F}^{-}$, and $\mathrm{Cl}^{-}$prepared from purified $\mathrm{WO}_{3}, \mathrm{NaF}$, and $\mathrm{NaCl}$, and carrying each solution through the entire analytical procedure. Table 2 lists the amounts of $\mathrm{F}^{-}$and $\mathrm{Cl}^{-}$present in the standardizing solutions together with the amounts of $\mathrm{Th}^{4+}$ and $\mathrm{Hg}^{++}$required to reach the respective end points. Because of the difficulty in determining the end point when large amounts of $\mathrm{SiF}_{6}{ }^{--}$are titrated with $\mathrm{Th}^{4+}$ using alizarin as indicator, titration volumes of less than three milliliters were used.

It has been reported that the amount of thorium solution necessary to produce the end point color with alizarin solution varies with the amount of precipitated thorium fluoride. ${ }^{8}$ Also, the fraction of the $\mathrm{F}^{-}$distilled as $\mathrm{H}_{2} \mathrm{SiF}_{6}$ depends upon the amount of $\mathrm{F}^{-}$present in the unknown solution. Rather than attempt corrections separately for each of the factors which introduce small errors in the fluorine analysis, it was decided to plot the volume of standard thorium solution as a function of known quantities of fluoride ion present in solutions made up to approximate in substances and concentrations the unknown solutions to be analyzed. A similar plot was constructed showing the quantity of standard mercuric ion as a function of chloride ion present in the starting solutions. The curves in Figures 2 and 3 show the dependence of the volumes of reagents upon the amounts of $\mathrm{F}^{-}$and $\mathrm{Cl}^{-}$ present in the standardizing solutions.

Sodium fluoride was recrystallized from water in beakers which had been coated inside with clear glyptal. A second preparation of sodium fluoride was made from repurified $\mathrm{NaHCO}_{3}$ and $48 \% \mathrm{HF}$ solution using glyptal coated beakers. It was found impossible to recrystallize sodium fluoride in pyrex glass equipment without severe contamination from the glass which was dissolved by the $\mathrm{HF}$ 


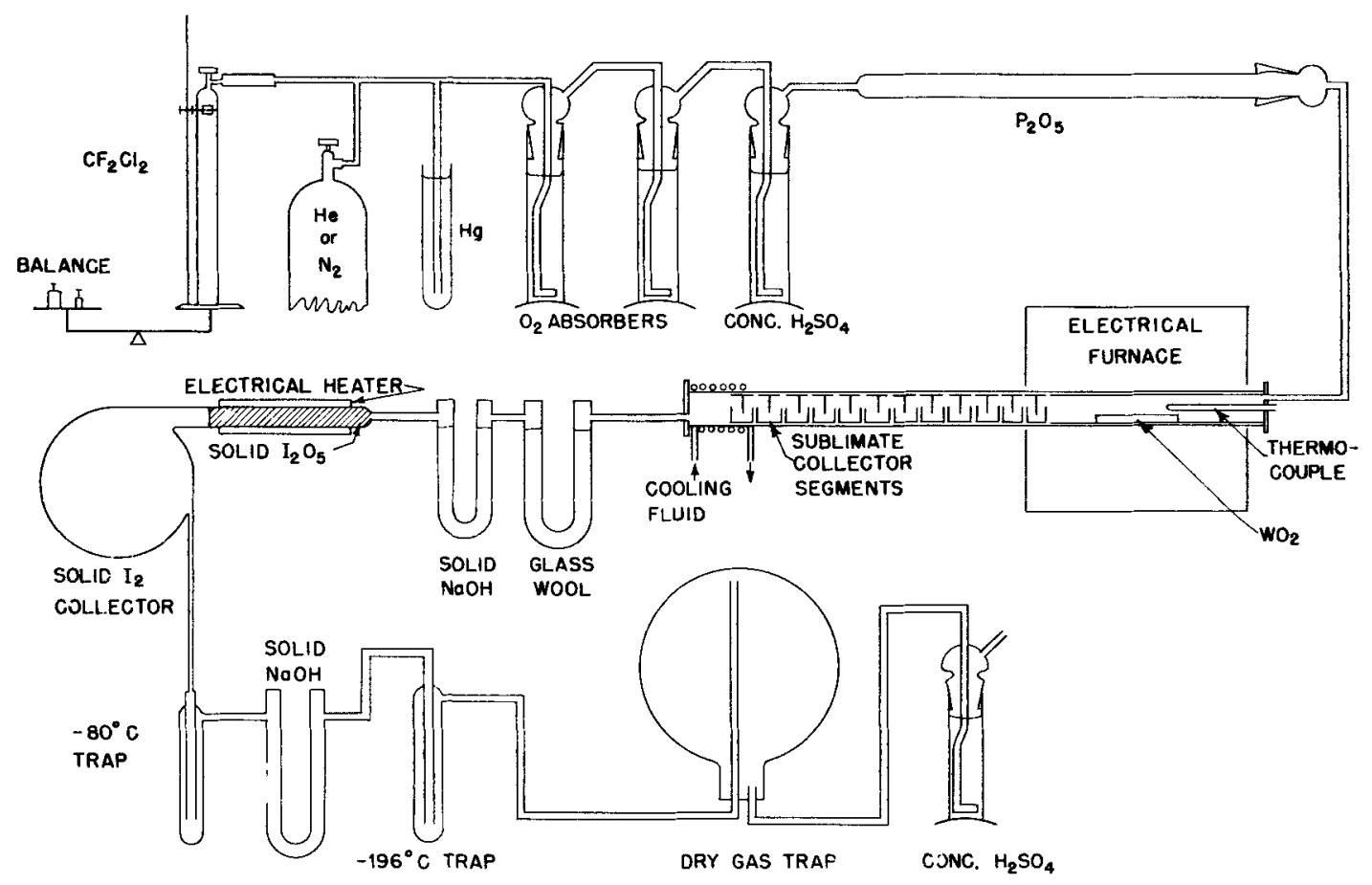

Figure 1.

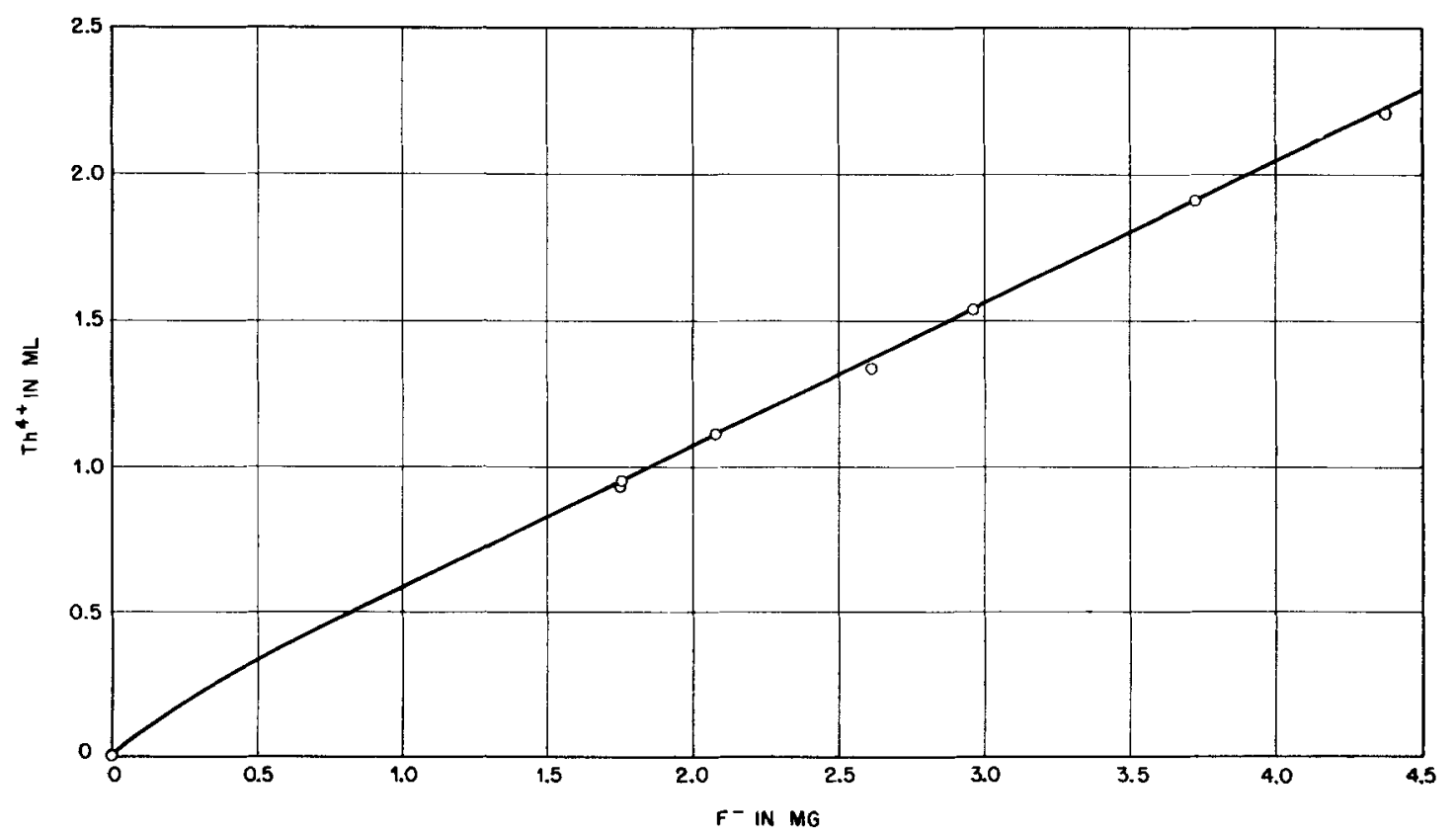

Figure 2. 
Table 2.

\begin{tabular}{lcccc}
\hline \hline $\begin{array}{l}\text { Standardizing } \\
\text { solution No. }\end{array}$ & $\begin{array}{c}\mathrm{F}^{-} \\
(\mathrm{mg})\end{array}$ & $\begin{array}{l}\mathrm{Th}^{4+} \\
(\mathrm{ml})\end{array}$ & $\begin{array}{l}\mathrm{Cl}^{-} \\
(\mathrm{mg})\end{array}$ & $\begin{array}{c}\mathrm{Hg}^{++} \\
(\mathrm{ml})\end{array}$ \\
\hline 1 & 0.0 & 0.01 & 0.0 & 0.05 \\
2 & 2.08 & 1.11 & 2.85 & 0.99 \\
2 (repeat) & 2.08 & 1.11 & - & - \\
3 & 2.61 & 1.34 & 3.56 & 1.18 \\
4 & 3.72 & 1.91 & 5.08 & 1.69 \\
5 & - & - & 7.12 & 2.24 \\
6 & $1.75^{*}$ & 0.93 & 3.56 & 1.20 \\
6 (repeat) & $1.75 *$ & 0.95 & 3.56 & 1.17 \\
7 & $4.37 *$ & 2.21 & 5.34 & 1.66 \\
8 & 2.96 & 1.54 & 2.27 & 0.82 \\
\hline
\end{tabular}

*Standardizing $\mathrm{NaF}$ prepared from $\mathrm{NaHCO}_{3}$ and $48 \% \mathrm{HF}$ solution.

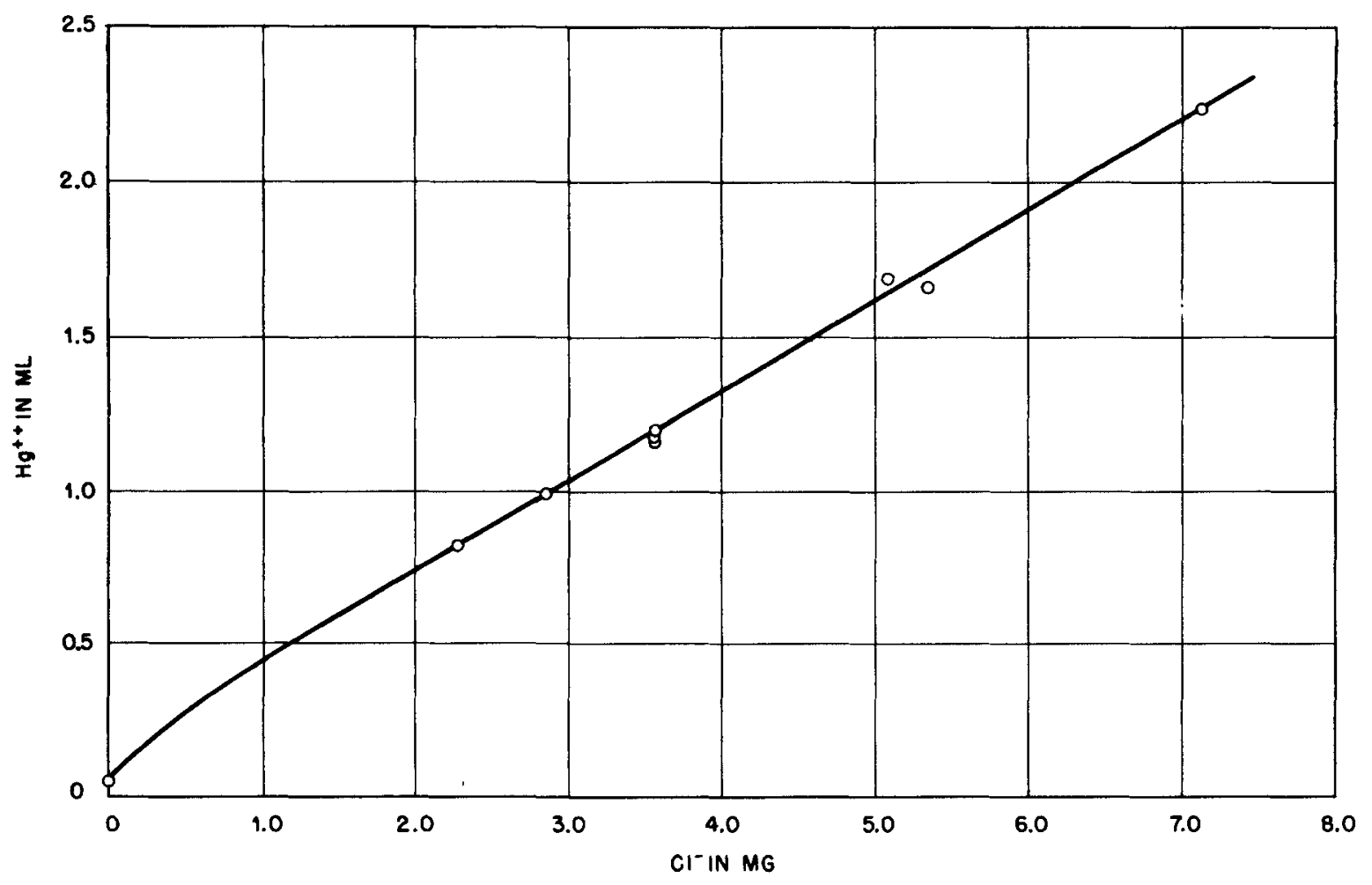

Figure 3. 
formed by hydrolysis. Points on the thorium ion-fluoride ion curve from either of the preparations of NaF were found to lie on a straight line. The linear relationship was found to hold between 1.7 and $4.5 \mathrm{mg}$. of fluoride ion. Between 0 and $1.7 \mathrm{mg}$. $\mathrm{F}^{-}$there was a slight dropping off in the curve, probably corresponding to the larger amount of thorium ion necessary to produce an end point pink color with larger amounts of precipitated thorium fluoride suspended in the solution.

The chloride ion in the standardizing solutions was obtained from recrystallized $\mathrm{NaCl}$. It was found that a linear dependence existed between $\mathrm{Cl}^{-}$and $\mathrm{Hg}^{++}$for values of $\mathrm{Cl}^{-}$from 2.0 to $8.0 \mathrm{mg}$. $\mathrm{Cl}^{-}$from 2.0 to $8.0 \mathrm{mg} \mathrm{Cl}{ }^{-}$. In the range from 0 to $2.0 \mathrm{mg} \mathrm{Cl}$ there was a slight dropping off of the curve which can be associated with variations in the distilling efficiency with variations in the amounts of $\mathrm{Cl}^{-}$.

The distilling apparatus was constructed so that a thermowell dipped into the liquid in the still pot. The heat input to the still pot was controlled by a thermocouple mounted in the thermowell so that the temperature of the liquid rose to $150^{\circ} \mathrm{C}$ and remained at $150^{\circ} \pm 3^{\circ} \mathrm{C}$ for the one hour period necessary to distill $200 \mathrm{ml}$ of liquid. Steam was supplied to the still pot at a constant rate from a small flash type boiler which was charged with distilled water at a constant rate by running the water through a section of capillary tube over which the reservoir water was maintained at a constant pressure and constant head. The rate of distillation was thus controlled by the air pressure over the distilled water in the reservoir. As it was found that distillation rates greater than $200 \mathrm{ml}$ per hour tended to carry over small amounts of precipitated $\mathrm{WO}_{3}$ from the still pot to the distillate, the air pressure over the water reservoir was so regulated that this distillation rate was not exceeded.

From the values listed there, Table 2 permits construction of the Curves in Figures 2 and 3. From the curves, it is possible to estimate the precision of the two analytical determinations of $F^{-}$ and of $\mathrm{Cl}^{-}$. We have no independent check of the accuracy of the determinations, however, since the system of standardizing the $\mathrm{Th}^{4+}$ and $\mathrm{Hg}^{++}$through titration of several $\mathrm{F}^{-}$and $\mathrm{Cl}^{-}$containing solutions is the only standardization of the $\mathrm{Th}^{4+}$ and $\mathrm{Hg}^{++}$made. For the linear portion of the curve relating the volume of thorium solution to the amount of fluoride ion present in the starting sample, the average deviation from the line was slightly less than $0.01 \mathrm{ml}$. The maximum deviation from the straight line was $0.02 \mathrm{ml}$. Since very few unknown samples were encountered in which the volume of thorium solution used was less than one milliliter, the uncertainty in the fluoride determination would be somewhat less than $1 \%$. The average of the deviations of the eight points used to establish the linear dependence of volume of $\mathrm{Hg}^{++}$solution on $\mathrm{Cl}^{-}$present in the starting solution was found to be $0.02 \mathrm{ml}$, with one point showing $0.06 \mathrm{ml}$ deviation from the straight line. The chloride ion determinations therefore were uncertain to the extent of about $2 \%$ when one milliliter of $\mathrm{Hg}^{++}$solution was used in the titration. The titrations were all made using $10 \mathrm{ml}$ microburets, and the titration flasks were illuminated with daylight type fluorescent tubes. For the fluoride titration a white surface showed up the first pink color to best advantage, while for the chloride ion titration the white turbidity of the end point was best seen against a black background.

\section{EXPERIMISNAL RESULTS}

The tungsten containing mixtures obtained from the collector segments at the termination of a reaction were of two general types. The material which solidified on the warmer collector segments had the crystal form characteristic of $\mathrm{WOCl}_{4}$, but a color from brown to orange while the compounds solidifying at lower temperatures were bright red-orange color with the same needle-like crystals. In some cases the cooler samples contained some liquid phase which was extremely reactive with traces of water vapor in the dry box, and was found by analysis to be $W_{6}$. In addition to the products obtained from the nickel collector segments inside the reactor tube, it was found that most of the $W_{6}$ was leaving the reactor and could be collected by a suitably cooler filter or absorbed in a tube of solid $\mathrm{NaOH}$ flakes. While the crystals which solidified in any one collector segment seemed to be homogenous, variation in composition with variation in the conditions of preparation would indicate that they were solid solutions. 
Addition of portions of the material obtained to water resulted in violent hydrolysis with immediate precipitation of yellow WO $_{3}$. The presence of tungsten in the +4 or +5 oxidation state would have resulted in a brown or blue color in the precipitated oxide. The crystal form and color were characteristic of $\mathrm{WOCl}_{4}$ rather than of an equimolar mixture of $\mathrm{WO}_{2} \mathrm{Cl}_{2}$ and $\mathrm{WCl}_{6}$. $\mathrm{WOCl}_{4}$ crystallizes in the form of long thin needles, $\mathrm{WCl}_{6}$ as dark blue cubes, and $\mathrm{WO}_{2} \mathrm{Cl}_{2}$ as pale yellow four sided plates. An equimolar mixture of $\mathrm{WCl}_{6}$ and $\mathrm{WO}_{2} \mathrm{Cl}_{2}$ therefore would be expected to have a green color and a mixed crystal form. Assuming from these facts that the tungsten present was in the maximum oxidation state, +6 , and that $\mathrm{WOCl}_{4}$ was present rather than the equimolar mixture of $\mathrm{WO}_{2} \mathrm{Cl}_{2}$ and $\mathrm{WCl}_{6}$, the analytical determinations of the total amounts of tungsten, fluorine, and chlorine, together with the total sample weight, could be used to calculate the composition of any mixture. $\mathrm{WO}_{2} \mathrm{~F}_{2}$ is unknown although its preparation has been attempted ${ }^{7}$, and $\mathrm{WF}_{6}$ has a vapor pressure of $760 \mathrm{~mm}$. $\mathrm{Hg}$ at $19.5^{\circ} \mathrm{C}$. Since the mixtures under investigation all were solid at $100^{\circ} \mathrm{C}$ or higher, $\mathrm{WF}_{6}$ is considered absent from the mixture. All of the fluorine present in the sample can then be calculated present as $\mathrm{WOF}_{4}$. The tungsten, chlorine, and oxygen remaining then are divided between $\mathrm{WCl}_{6}$ and $\mathrm{WOCl}_{4}$. Knowledge of the quantities of tungsten and chlorine is sufficient to permit calculation of the amounts of $\mathrm{WCl}_{6}$ and $\mathrm{WOCl}_{4}$ present. We can use our knowledge of the amount of oxygen present as a check of our method. The fact that we find agreement within the limits of the analytical accuracy is proof that our choice of substances present in the mixture is correct. Table 3 reports the analyses and calculated compositions for several of the fractions obtained in various runs. The calculated oxidation numbers for the tungsten as tabulated in Table 3 show a relatively large deviation from the value 6 . These oxidation numbers were obtained by using the analytically determined amounts of oxygen found, and consequently reflect the large percentage error of the oxygen value. Comparison of samples 8-41 and 8-79, which were obtained by fractionation of the product from run 8, shows the degree of separation obtained by the fractionation collector segments. The mixture solidifying on the $200^{\circ} \mathrm{C}$ collector segment is essentially pure $\mathrm{WOCl}_{4}$ while the material collected on a segment $90^{\circ} \mathrm{C}$ cooler is essentially half WOF $_{4}$ and half wOCl 4 .

Several substances which did not contain any tungsten were found to result from the reaction of $\mathrm{WO}_{2}$ with $\mathrm{CF}_{2} \mathrm{Cl}_{2}$. Those formed in largest amounts were elemental carbon, carbon monoxide, which was detected by oxidation to $\mathrm{CO}_{2}$ by $\mathrm{I}_{2} \mathrm{O}_{5}$, carbon dioxide, which was absorbed in solid $\mathrm{NaOH}$ tubes and weighed, phosgene, which was absorbed in solid $\mathrm{NaOH}$ and also detected by odor in separate runs, and a gas, absorbed in solid $\mathrm{NaOH}$, which contained fluorine and by calculation must have been $\mathrm{COF}_{2}$. Carbon has been reported as a catalyst for the reaction between $\mathrm{WO}_{3}$ and $\mathrm{Cl}_{2},{ }^{8}$ but this work makes the first report of the production of carbon in a reaction between any tungsten oxide and a halomethane. In addition to the above mentioned substances varying amounts of fluorochlorocarbons of high melting point with odors similar to that of $\mathrm{C}_{2} \mathrm{Cl}_{6}$ were found, but attempts to collect quantities large enough for analysis were unsuccessful.

The elemental carbon formed by the reaction was deposited in the boat in which the $\mathrm{WO}_{2}$ was contained in mechanical form identical with that of the $\mathrm{WO}_{2}$ which it replaced. In addition, traces of carbon were found on those nickel surfaces inside the reactor which were heated to $500^{\circ} \mathrm{C}$ or more. This latter carbon film probably resulted from the catalytic decomposition of some of the carbon monoxide.

The exit gases from the nickel reactor tube were led through a large tube filled with solid flakes of $\mathrm{NaOH}$, which served to absorb $\mathrm{WF}_{6}, \mathrm{COF}_{2}, \mathrm{COCl}_{2}$, and $\mathrm{CO}_{2}$. The weight increase in the tube of $\mathrm{NaOH}$ in addition to determinations of the amounts of $\mathrm{W}^{6+}, \mathrm{F}^{-}$, and $\mathrm{Cl}^{-}$present enabled calculation of the amounts of the above mentioned substances present. All of the tungsten present is calculated to be $\mathrm{WF}_{6}$ as the first step. The fluorine remaining is assumed to have come from $\mathrm{COF}_{2}$ and all of the chlorine is assumed to have come from $\mathrm{COCl}_{2}$. The difference between the gain in weight of the $\mathrm{NaOH}$ absorber tube and the total weights of $\mathrm{WF}_{6}, \mathrm{COF}_{2}$, and $\mathrm{COCl}_{2}$ is then the weight of $\mathrm{CO}_{2}$ produced in the reaction.

From the tube of solid $\mathrm{NaOH}$ flakes, the gas stream was led over solid $\mathrm{I}_{2} \mathrm{O}_{5}$ which was heated to 
Table 3.

\begin{tabular}{|c|c|c|c|c|c|c|c|c|c|c|c|}
\hline $\begin{array}{l}\text { Run } \\
\text { No. }\end{array}$ & $\begin{array}{l}\text { Melting } \\
\text { temp. } \\
\left({ }^{\circ} \mathrm{C}\right)\end{array}$ & $\begin{array}{l}w \\
(w t \\
\%)\end{array}$ & $\begin{array}{c}F \\
\text { (wt } \\
\%)\end{array}$ & $\begin{array}{l}\mathrm{Cl} \\
(w \mathrm{t} \\
\%)\end{array}$ & $\begin{array}{c}0 \\
(w t \\
\%)\end{array}$ & $\begin{array}{c}\mathrm{WCl}_{6} \\
(\mathrm{~mole} \\
\%)\end{array}$ & $\begin{array}{c}\mathrm{WOCl}_{4} \\
(\mathrm{~mole} \\
\%)\end{array}$ & $\begin{array}{c}\text { WOF }_{4} \\
\text { (mole } \\
\%)\end{array}$ & $\begin{array}{c}\mathrm{WF}_{6} \\
(\mathrm{~mole} \\
\%)\end{array}$ & $\begin{array}{l}\mathrm{x}^{-} / \mathrm{W} \\
\text { (mole } \\
\text { ratio) }\end{array}$ & $\begin{array}{l}\text { Calc. } \\
\text { Ox. No. } \\
\text { W }\end{array}$ \\
\hline $8-41$ & 110 & 57.5 & 9.8 & 27.8 & 4.9 & 7.7 & 51.1 & 41.2 & 0.0 & 4.15 & 6.11 \\
\hline $8-79$ & 200 & 53.7 & 1.3 & 40.8 & 4.2 & 8.6 & 85.6 & 5.8 & 0.0 & 4.17 & 5.96 \\
\hline $8-61$ & 20 & 67.7 & 12.0 & 2.5 & 11.4 & * & & & & 1.92 & 5.80 \\
\hline 8-fil & 20 & 62.6 & 42.9 & 0.0 & 0.0 & 0.0 & 0.0 & 0.0 & $100.0 \dagger$ & 6.60 & 6.60 \\
\hline $9-41$ & 110 & 58.9 & 12.1 & 23.2 & 5.8 & 0.0 & 50.8 & 49.2 & 0.0 & 4.02 & 6.28 \\
\hline $9-13$ & 155 & 55.4 & 4.9 & 35.1 & 4.6 & 7.3 & 71.1 & 21.6 & 0.0 & 4.14 & 6.06 \\
\hline 9-fil & -10 & 55.4 & 40.6 & 2.6 & - & 0.0 & 0.0 & 0.0 & $100.0 \ddagger$ & 7.07 & 7.07 \\
\hline $10-41$ & 155 & 58.2 & 10.6 & 25.5 & 5.8 & 0.0 & 56.4 & 43.6 & 0.0 & 4.03 & 6.31 \\
\hline $10-42$ & 200 & 56.1 & 5.9 & 32.6 & 5.4 & 0.0 & 74.9 & 25.1 & 0.0 & 4.02 & 6.24 \\
\hline 10-fil & 20 & - & - & - & - & 0.0 & 0.0 & 0.0 & $100.0 \S$ & 6.07 & - \\
\hline $11-13$ & 155 & 59.1 & 12.0 & 22.7 & 6.2 & 0.0 & 50.1 & 49.9 & 0.0 昔 & 3.94 & 6.36 \\
\hline $11-41$ & 200 & 58.9 & 11.1 & 25.1 & 4.9 & 0.0 & 54.9 & 45.1 & $0.0_{\pi}$ & 4.02 & 5.96 \\
\hline
\end{tabular}

${ }^{*} \mathrm{H}_{2} \mathrm{O}=6.1 \%$ by weight. Product can be $\mathrm{WO}_{2} \mathrm{~F}_{2} \cdot \mathrm{H}_{2} \mathrm{O}$ or $\mathrm{WO}_{3} \cdot 2 \mathrm{HF}$.

$1105.5 \%$ recovery due to high silica content and small sample size.

†Glass wool filter absorbs some $\mathrm{COF}_{2}$.

§ Total sample weight unknown. No $\mathrm{Cl}^{-}, .00575$ moles $\mathrm{F}^{-}$, and .000947 moles $\mathrm{W}^{6+}$.

\# High gas flow rate through reactor results in little fractionation.

$160^{\circ} \pm 5^{\circ} \mathrm{C}$ in order to oxidize the $\mathrm{CO}$ in the gas stream. ${ }^{\circ}$ The $\mathrm{I}_{2}$ produced was collected in a large air-cooled settling bulb followed by a trap held at $-80^{\circ} \mathrm{C}$ by a dry ice-acetone mixture. The $\mathrm{CO}_{2}$ re-sulting from the oxidation of $\mathrm{CO}$ was absorbed in another tube filled with solid NaOH flakes. Spot tests on the solution obtained by dissolving the solid $\mathrm{NaOH}$ flakes showed no $\mathrm{F}^{-}$nor $\mathrm{Cl}^{-}$which indicated that no freon type compound was being oxidized by the heated $\mathrm{I}_{2} \mathrm{O}_{5}$. In addition, the amounts of $\mathrm{I}_{2}$ and $\mathrm{CO}_{2}$ obtained were in the molar ratio $\mathrm{CO}_{2}$ to $\mathrm{I}_{2}=5.0$, which corresponds to the oxidation of $\mathrm{CO}$ rather than some other substance. It was necessary to warm the trap at $-\mathrm{BO}^{\circ} \mathrm{C}$ at intervals in order to distill the small amounts of liquid freon which condensed. Also a small correction was necessary for the amount of $I_{2}$ which was carried into the solid $\mathrm{NaOH}$ tube.

From the second tube of solid NaOH flakes the gas stream was led through a trap cooled with liquid nitrogen in which the unreacted freon was collected as solid. Following the freon condensing trap the gas passed through a large reservoir of $\mathrm{N}_{2}$ or $\mathrm{He}$ and exited to the atmosphere through a water vapor removing train.

Since it had been observed in preliminary experiments that $\mathrm{CF}_{2} \mathrm{Cl}_{2}$ reacted with pyrex glass at temperatures near $500^{\circ} \mathrm{C}$, it was of interest to determine whether there was decomposition on passing the gas through the nickel tube and carbon boat equipment. The equipment was set up exactly as it was for all of the runs with reaction between $\mathrm{WO}_{2}$ and $\mathrm{CF}_{2} \mathrm{Cl}_{2}$ with two exceptions, first, no $\mathrm{WO}_{2}$ was charged, and second, a tube of antimony metal filings was included in the gas analysis train, being placed between the reactor tube and the first $\mathrm{NaOH}$ absorber tube. Two runs were made in which operating conditions duplicated those generally used. In the first experiment some $30 \%$ of the freon 
charged reacted, while in the second run the comparable figure was $19 \%$. The weight of the freon reacted was obtained by subtracting the weight of freon condensed in the liquid nitrogen trap at the end of the analytical train from the weight of freon charged to the reactor. The charging rates for the freon were nearly identical in each experiment, but in the first experiment nitrogen was used as flushing gas where He was used in the second case. In both experiments small quantities of COF 2 were collected in the solid $\mathrm{NaOH}$ absorber tube, while there was no weight increase in the tube filled with granulated antimony metal through which the gas stream passed before reaching the solid NaOH absorber.

If there had been any $\mathrm{Cl}_{2}, \mathrm{~F}_{2}$, or CIF in the gas stream, there would have been reactions to give $\mathrm{SbCl}_{3}$ or $\mathrm{SbF}_{3}$ with a weight increase in the tube proportional to the amount of halogen absorbed. ${ }^{10}$ As a check of the efficiency of the antimony metal as a $\mathrm{Cl}_{2}$ absorber, aliquots of the solution obtained from dissolving the contents of the first $\mathrm{NaOH}$ absorber tube were checked for the presence of $\mathrm{ClO}^{-}$. Absence of $\mathrm{ClO}^{-}$in the $\mathrm{NaOH}$ absorber solution indicates that no free halogen reached the solid NaOH. In the second experiment some $\mathrm{COCl}_{2}$ also was collected in the $\mathrm{NaOH}$ absorber tube. Furthermore, the second experiment was found to produce a small quantity of $\mathrm{CO}$. In the first experiment the CO oxidizer was not operating. As all of the oxygen was removed from the incoming freon, the oxygen which appeared as $\mathrm{CO}$ must have been adsorbec on the carbon boat and the internal surfaces of the reactor. This oxygen was firmly enough adsorbed so that it was not liberated on the passage of He through the reactor tube at a temperature of $525^{\circ} \mathrm{C}$, but when the freon flow was started the CO began to appear at the end of the tube. After some 20 minutes of freon flow the appearance of $\mathrm{CO}$ at the end of the reactor had ceased. The amount of $\mathrm{CO}$ adsorbed during the freon cracking reaction is less than 1 percent of that formed when the freon reacts with $\mathrm{WO}_{2}$.

Calculating from the amounts of $\mathrm{Cl}^{-}$and $\mathrm{F}^{-}$in the solution obtained by washing out the reactor after the experiments together with the amounts of $\mathrm{CF}_{2} \mathrm{Cl}_{2}$ used up one finds that $\mathrm{C}_{2} \mathrm{~F}_{4} \mathrm{Cl}_{2}$ and $\mathrm{C}_{2} \mathrm{~F}_{3} \mathrm{Cl}_{3}$ are likely products. One can visualize the production of $\mathrm{C}_{2} \mathrm{~F}_{4} \mathrm{Cl}_{2}$ as resulting from the combination of two $\mathrm{CF}_{2} \mathrm{Cl}$ free radicals which would be likely first products of the thermal cracking of the $\mathrm{CF}_{2} \mathrm{Cl}_{2}$ molecule. In a similar manner, $\mathrm{C}_{2} \mathrm{~F}_{3} \mathrm{Cl}_{3}$ would result from the union of $\mathrm{CF}_{2} \mathrm{Cl}$ and $\mathrm{CFCl}_{2}$ free radicals. The smaller amount of the $\mathrm{C}_{2} \mathrm{~F}_{3} \mathrm{Cl}_{3}$ found reflects the smaller amount of $\mathrm{CFCl}_{2}$ produced, which is reasonable since more energy is required to break the $\mathrm{C}-\mathrm{F}$ bond than is required to break the $\mathrm{C}-\mathrm{Cl}$ bond. The compound, $\mathrm{C}_{2} \mathrm{~F}_{2} \mathrm{Cl}_{4}$, was not considered a likely product since its formation would require a relatively larger concentration of $\mathrm{CFCl}_{2}$ radicals as compared to $\mathrm{CF}_{2} \mathrm{Cl}$ radicals. The results of the two freon cracking experiments are presented in Table 4. Both of the runs were made at a temperature of $625^{\circ} \mathrm{C}$.

\section{CONCLUSHONS}

Table 5 presents the results of several runs made at $525^{\circ} \mathrm{C}$ in which determination of the quantities of nearly all of the substances involved in the reactions was made. High ratios of freon reacted to $\mathrm{WO}_{2}$ reacted as shown in line 17 of Table 5 are observed to correspond with high ratios of halide ion to tungsten lon in the wash solution, as shown in line 15 of Table 5. A correspondence of this type confirms the idea of the occurrence of a freon cracking reaction with production of chlorine and fluorine which subsequently react with the nickel metal at the same time as the $\mathrm{WO}_{2}-\mathrm{CF}_{2} \mathrm{Cl}_{2}$ reaction is taking place. The lack of correlation observed between rate of freon addition and product distribution indicates a surface type reaction for the cracking of the freon molecules as well as for the reaction between the freon and $\mathrm{WO}_{2}$. Compare run 10 with a freon introduction rate of $27.7 \mathrm{~g}$ per hour and a halide ion to tungsten ion ratio of 4.34 with run 12 in which the freon introduction rate was $11.4 \mathrm{~g}$ per hour while the halide to tungsten ion ratio was 4.27 . In each run the amount of $W$ reacting was. .066 gram-atoms. If the freon decomposition were a gas phase reaction we should find a much higher halide ion to tungsten ion ratio when there was a greater quantity of freon introduced. From the facts that the halide ion to tungsten ion ratio is not sensitive to the quantity of freon introduced, we conclude that the freon decomposition occurs on the surface and is there limited by some factor other 
Table 4.

\begin{tabular}{|c|c|c|}
\hline & Run 1 & Run 2 \\
\hline $\begin{array}{l}\mathrm{CF}_{2} \mathrm{Cl}_{2} \text { charge rate, } \\
\text { grams per hour }\end{array}$ & 11.1 & 10.7 \\
\hline $\mathrm{CF}_{2} \mathrm{Cl}_{2}$ reacted, moles & $.0491 \pm .004$ & $.0248 \pm .004$ \\
\hline $\begin{array}{l}\% \text { of } \mathrm{CF}_{2} \mathrm{Cl}_{2} \text { charged } \\
\text { which reacted }\end{array}$ & 30.1 & 18.8 \\
\hline $\begin{array}{l}\text { analysis reactor wash } \\
\text { solution showed } \\
\text { total } \mathrm{F}^{-} \text {, gram-atoms } \\
\text { total } \mathrm{Cl}^{-} \text {, gram-atoms }\end{array}$ & $\begin{array}{l}.0080 \\
.0402\end{array}$ & $\begin{array}{l}.0032 \\
.0221\end{array}$ \\
\hline $\begin{array}{l}\text { Wt. gain of Sb metal } \\
\text { absorber tube }\end{array}$ & 0.0 & 0.0 \\
\hline $\begin{array}{l}\text { Wt. gain solid NaOH } \\
\text { absorber tube, grams } \\
\text { Calculated composition } \\
\text { of gases absorbed }\end{array}$ & .2065 & .0390 \\
\hline $\begin{array}{l}\mathrm{COF}_{2}, \text { moles } \\
\mathrm{COCl}_{2}, \text { moles }\end{array}$ & $\begin{array}{l}.00088 \\
0.0\end{array}$ & $\begin{array}{l}.00040 \\
.00010\end{array}$ \\
\hline CO found, moles & - & .00012 \\
\hline $\begin{array}{l}\text { Non-water soluble } \\
\text { reaction products, } \\
\text { calculated }\end{array}$ & & \\
\hline $\begin{array}{l}\mathrm{C}_{2} \mathrm{~F}_{4} \mathrm{Cl}_{2}, \text { moles } \\
\mathrm{C}_{2} \mathrm{~F}_{3} \mathrm{Cl}_{3}, \text { moles }\end{array}$ & $\begin{array}{l}.0157 \\
.0089\end{array}$ & $\begin{array}{l}.0092 \\
.0040\end{array}$ \\
\hline
\end{tabular}

than the quantity of freon present in the gas phase. The lack of correlation between the amounts of carbon and carbon dioxide found in every run indicates that these substances are not formed entirely by decomposition of $\mathrm{CO}$ on the catalytic surfaces present.

Recent investigations have shown that the rutile structure is distorted in the case of $\mathrm{wO}_{2}$ to the extent that the tungsten atoms in adjacent octahedra are drawn to within $2.48 \mathrm{~A}$. of one another from their non-bonded or average distance of $2.77 \mathrm{~A} . .^{11}$ The edges of the octahedra through which this closer approach occurs are correspondingly lengthoned. The Pauling bond number associated with this shorter distance between tungsten atoms is 1.47 which indicates a tendency toward use of the extra valence electrons of the two tungsten atoms in $\mathrm{WO}_{2}$ to form a double bond between them. ${ }^{12}$ It is interesting to note that the triangle formed by the two bonded tungsten atoms and one of the oxygen atoms forming the expanded edge of the touching octahedra is almost a perfect fit for the face of the freon tetrahedron, which has a distance of $2.53 \mathrm{~A}$ between fluorine and chlorine atoms. The $\mathrm{F}-\mathrm{Cl}$ distance together with the $\mathrm{F}-\mathrm{F}$ distance of $2.20 \mathrm{~A}$ and the $\mathrm{Cl}-\mathrm{Cl}$ distance of $2.85 \mathrm{~A}$ are calculated from electron diffraction data by Brockway ${ }^{13}$ assuming that tetrahedral angles prevail in $\mathrm{CF}_{2} \mathrm{Cl}_{2}$. There is sufficient room on the crystal face of $\mathrm{WO}_{2}$ for four freon tetrahedron faces to fit around each bonded pair of tungsten atoms. It is proposed therefore that the first step in the reaction between $\mathrm{WO}_{2}$ and $\mathrm{CF}_{2} \mathrm{Cl}_{2}$ is the adsorption of four $\mathrm{CF}_{2} \mathrm{Cl}_{2}$ molecules about each bonded pair of tungsten atoms in the surface of the $\mathrm{WO}_{2}$ crystal. The large number of ways in which this complex could dissociate then accounts for the variety of products obtained in the reaction. 
Table 5.

\begin{tabular}{|c|c|c|c|c|c|c|c|}
\hline & Run 9 & Run 10 & Run 11 & Run 12 & Run 13 & Run 14 & Run 16 \\
\hline $\begin{array}{l}\text { W reacted, } \\
\text { gram-atoms }\end{array}$ & .0742 & .0666 & .1067 & .0663 & .0474 & .0709 & .0057 \\
\hline $\begin{array}{l}\mathrm{CF}_{2} \mathrm{Cl}_{2} \text { re- } \\
\text { acted, mols }\end{array}$ & .132 & - & - & - & .0561 & .0991 & .0198 \\
\hline Temp., ${ }^{\circ} \mathrm{C}$ & 525 & 525 & 525 & 525 & 525 & 525 & 525 \\
\hline $\begin{array}{l}\text { Time reactor } \\
\text { at } 525^{\circ} \mathrm{C}, \mathrm{hrs}\end{array}$ & 3.8 & 4.0 & 5.0 & 3.25 & 3.0 & 2.75 & 2.0 \\
\hline $\begin{array}{l}\text { Rate of } \mathrm{CF}_{2} \mathrm{Cl}_{2} \\
\text { charge, } \mathrm{g} / \mathrm{hr}\end{array}$ & 11.2 & 27.2 & 24.0 & 11.4 & 6.3 & 6.9 & 5.3 \\
\hline Carrier gas & none & none & none & none & $\mathbf{N}_{2}$ & $\mathrm{~N}_{2}$ & $\mathrm{He}$ \\
\hline \multicolumn{8}{|c|}{$\begin{array}{l}\text { Reaction products } \\
\text { obtained }\end{array}$} \\
\hline $\begin{array}{l}\text { C, gram-atoms } \\
\mathrm{CO} \text {, moles }\end{array}$ & $\begin{array}{l}.01059 \\
-\end{array}$ & $\begin{array}{l}.0149 \\
-\end{array}$ & $\begin{array}{l}.01621 \\
.1051\end{array}$ & $\begin{array}{l}.0109 \\
.0665\end{array}$ & $\overline{-} .0423$ & $\begin{array}{l}.01265 \\
.0683\end{array}$ & $\begin{array}{l}.000866 \\
.0030\end{array}$ \\
\hline $\mathrm{CO}_{2}$, moles & - & - & .00459 & .00311 & .00314 & .00066 & .000689 \\
\hline $\mathrm{COF}_{2}$, moles & - & .00126 & .00215 & .00107 & .00232 & .00135 & .00239 \\
\hline $\mathrm{COCl}_{2}$ moles & - & - & .00082 & .00024 & .00161 & .00166 & .000497 \\
\hline $\begin{array}{l}\text { Analysis reactor } \\
\text { wash and sample } \\
\text { showed, } \\
\text { total W, g-at }\end{array}$ & - & .0475 & .1019 & .0622 & .0455 & .0649 & .00515 \\
\hline total $F^{-}, g-a t$ & - & .1131 & .2302 & .1473 & .1321 & .1580 & .0185 \\
\hline total $\mathrm{Cl}^{-}, \mathrm{g}-$ at & - & .0931 & .1712 & .1187 & .1251 & .1670 & .0333 \\
\hline $\begin{array}{l}\text { Mole ratios } \\
\mathrm{x}^{-} / \mathrm{w}\end{array}$ & - & 4.34 & 3.95 & 4.27 & 5.64 & 5.01 & 10.96 \\
\hline $\mathrm{w} / \mathrm{C}$ & 7.01 & 4.47 & 6.58 & 6.08 & - & 5.61 & 6.58 \\
\hline $\mathrm{CF}_{2} \mathrm{Cl}_{2} / \mathrm{W}$ & 1.78 & - & - & - & 1.19 & 1.40 & 3.48 \\
\hline $\mathrm{w} / \mathrm{CO}$ & - & - & 1.02 & 0.99 & 1.12 & 1.05 & 1.90 \\
\hline
\end{tabular}

Moreover, uncontrolled variations in the surface of the $\mathrm{WO}_{2}$ in different runs would have large effects upon the products obtained.

The ratio of tungsten reacted to carbon produced as tabulated in line 16 of Table 5 is found to be on the average near 6 , while the ratio of tungsten reacted to $\mathrm{CO}$ produced shown in line 18, Table 5, is near unity. Also the ratio of total halide ion to total tungsten ion in the wash solution and samples, as shown in line 15 of Table 5, is approximately 4 in all but run 16 in which case a much higher freon to tungsten ratio also occurs. One concludes from these ratios that the path of lowest energy barrier for the decomposition of the complex is the one resulting in the formation of $\mathrm{CO}$ and tungsten in its maximum oxidation state. The stoichimetry of the principal reaction between $\mathrm{WO}_{2}$ and $\mathrm{CF}_{2} \mathrm{Cl}_{2}$ at $525^{\circ} \mathrm{C}$ then could be expressed by the equation, $2 \mathrm{WO}_{2}+2 \mathrm{CF}_{2} \mathrm{Cl}_{2}=\mathrm{WOF}_{4}+\mathrm{WOCl}_{4}+2 \mathrm{CO}$. The decomposition of the complex resulting in carbon as a product would require the removal of oxygen in the form of $\mathrm{COCl}_{2}, \mathrm{COF}_{2}$, or $\mathrm{CO}_{2}$ with tungsten going off as volatile halides or oxyhalides. The 
production of $\mathrm{WCl}_{6}$ and $\mathrm{WF}_{6}$ could come about from complex decomposition along another path or from a secondary gas phase reaction of the $\mathrm{WOCl}_{4}$ produced by the main reaction just given with $\mathrm{COCl}_{2}$ to give $\mathrm{WCl}_{6}$ and $\mathrm{CO}_{2} . \mathrm{WF}_{6}$ might be produced by an analogous reaction between $\mathrm{COF}_{2}$ and WOF $_{4}$. The phosgene and fluorophosgene could result from a gas phase combination of CO from the main reaction with $\mathrm{Cl}_{2}$ or $\mathrm{F}_{2}$ from the decomposition of the freon.

Comparison of the work reported in this paper with the only other published study of a reaction between $\mathrm{CF}_{2} \mathrm{Cl}_{2}$ and a heavy metal oxide, that of Booth, Krasny-Ergen, and Heath, shows wide but reasonable contrasts. Whereas Booth and coworkers found that freon would act as a reducing agent for $\mathrm{UO}_{3}$, we found that freon molecule is capable of oxidizing $\mathrm{WO}_{2}$, both reactions occurring in the same temperature range. A search of the literature shows that many persons have found occasion to add carbon to tungsten ores in various processes of purification, ${ }^{14}$ in which processes carbon seems to function either as reducing agent or as catayst for the reaction between $\mathrm{Cl}_{2}$ and $\mathrm{WO}_{3}$, but no mention is found of carbon being produced by any reaction with tungsten oxides. One case of production of carbon is reported. ${ }^{15}$ The reaction between phosgene and metallic tungsten is reported to produce carbon, $\mathrm{WOCl}_{4}$, and traces of $\mathrm{WCl}_{5}$ and $\mathrm{WCl}_{6}$.

For purposes of comparison we investigated the reaction between $\mathrm{CCl}_{4}$ and $\mathrm{WO}_{2}$ at temperatures near $350^{\circ} \mathrm{C}$. The results of two runs are presented in Table 6 . The only tungsten containing volatile product was found to be $\mathrm{WOCl}_{4}$, while carbon was deposited in the $\mathrm{WO}_{2}$ charge boat as it did in the freon-WO $\mathrm{O}_{2}$ reaction. From the variable and high ratio of tungsten reacted to carbon produced, we can calculate that the main reaction must be $\mathrm{WO}_{2}+\mathrm{CCl}_{4}=\mathrm{WOCl}_{4}+\mathrm{CO}$. The carbon can result either from decomposition of some of the $\mathrm{CO}$ according to the equation $2 \mathrm{CO}=\mathrm{C}+\mathrm{CO}_{2}$ or from a second reaction between the tungsten dioxide and the carbon tetrachloride as shown by the equation $2 \mathrm{WO}_{2}+2 \mathrm{CCl}_{4}=2 \mathrm{WOCl}_{4}+\mathrm{C}+\mathrm{CO}_{2}$. The similarity of products and of tungsten to carbon ratios in the two reacting systems, $\mathrm{WO}_{2}-\mathrm{CCl}_{4}$ and $\mathrm{WO}_{2}-\mathrm{CF}_{2} \mathrm{Cl}_{2}$ is gratifying.

The substitution of $\mathrm{WO}_{3}$ for $\mathrm{WO}_{2}$ in a reaction with $\mathrm{CCl}_{4}$ was tried in one experiment which is also reported in Table 6. The most impressive difference between the reaction of $\mathrm{CCl}_{4}$ and $\mathrm{WO}_{3}$ as compared with the reaction of $\mathrm{CCl}_{4}$ and $\mathrm{WO}_{2}$ is the lack of production of carbon in the first named reaction. The volatile tungsten containing products in the $\mathrm{WO}_{3}-\mathrm{CCl}_{4}$ reaction are of two types, wOCl 4 and $\mathrm{WO}_{2} \mathrm{Cl}_{2}$ which are easily differentiated by their crystal forms and color. Contrary to the literature which reports ${ }^{20} \mathrm{CO}_{2}$ as the only gaseous product we find $\mathrm{COCl}_{2}$ present also. Our temperature, however, was $350^{\circ} \mathrm{C}$ while that reported in the literature is red-heat, and there could easily be enough change in type of reaction to make $\mathrm{CO}_{2}$ the primary gaseous product at this higher temperature. The equation for the reaction occurring at $350^{\circ} \mathrm{C}$ may be written as $2 \mathrm{WO}_{3}+2 \mathrm{CCl}_{4}=$ $\mathrm{WO}_{2} \mathrm{Cl}_{2}+\mathrm{WOCl}_{4}+\mathrm{COCl}_{2}+\mathrm{CO}_{2}$, while that from the literature is given as $3 \mathrm{WO}_{3}+2 \mathrm{CCl}_{4}=$ $2 \mathrm{WO}_{2} \mathrm{Cl}_{2}+\mathrm{WOCl}_{4}+2 \mathrm{CO}_{2}$.

The reaction between $\mathrm{WO}_{3}$ and $\mathrm{CCl}_{4}$ discussed may be contrasted with the behavior of the system $\mathrm{WO}_{3}-\mathrm{CF}_{2} \mathrm{Cl}_{2}$ at temperatures up to $600^{\circ} \mathrm{C}$ in which no evidence of any reaction could be found.

As a further interesting comparison we attempted to react $\mathrm{CF}_{4}$ with $\mathrm{WO}_{2}$, but found that there was no reaction at any temperature up to and including $700^{\circ} \mathrm{C}$.

\section{SUMMARY}

The reactions between freon, $\mathrm{CF}_{2} \mathrm{Cl}_{2}$, and $\mathrm{WO}_{2}$ were studied at a temperature of $525^{\circ} \mathrm{C}$ and atmospheric pressure.

Several types of reactors were used. Glass equipment was unsuitable because of the decomposition of $\mathrm{CF}_{2} \mathrm{Cl}_{2}$ at $500^{\circ} \mathrm{C}$ and higher with resultant attack of pyrex glass by some of the decomposition products. The reactor used finally was of pure nickel, designed so that partial fractionation of the subliming reaction products was obtained. Fractionation resulted from passing the products through 
Table 6. Reactions between $\mathrm{CCl}_{4}$ and $\mathrm{WO}_{2}$ or $\mathrm{WO}_{3}$ with products formed.

\begin{tabular}{|c|c|c|c|}
\hline & Run 1 & Run 2 & Run 3 \\
\hline Oxide reacted & $\mathrm{WO}_{2}$ & $\mathrm{wO}_{2}$ & $\mathrm{wo}_{3}$ \\
\hline Reaction temp., ${ }^{\circ} \mathrm{C}$ & 360 & 375 & 350 \\
\hline $\mathrm{CCl}_{4}$ charge rate, $\mathrm{ml} / \mathrm{min}$ & .044 & .044 & .044 \\
\hline Oxide charged, grams & .5992 & .5948 & .5088 \\
\hline Oxide reacted, grams & .3419 & .4393 & .4661 \\
\hline $\mathrm{WO}_{2} \mathrm{Cl}_{2}$ produced & No & No & Yes \\
\hline woCl $_{4}$ produced & Yes & Yes & Yes \\
\hline C produced, grams & .0069 & .0076 & 0.0 \\
\hline $\mathrm{COCl}_{2}$ produced & No & No & Yes \\
\hline $\mathrm{w} / \mathrm{C}$ mole ratio & 2.75 & 3.21 & - \\
\hline
\end{tabular}

twelve specially designed collector segments, each containing three baffles, while a temperature gradient of $525^{\circ} \mathrm{C}$ was maintained over the distance filled by the twelve collector segments.

Analysis of the volatile tungsten containing products separated by means of the nickel fractionating system showed the presence of $\mathrm{WCl}_{6}, \mathrm{WF}_{6}$, $\mathrm{WOCl}_{4}$, and $\mathrm{WOF}_{4}$. The latter two products constituted the larger proportion of tungsten containing products obtained. In addition to the four tungsten containing products, the following were found to result in larger or smaller amounts, $\mathrm{C}, \mathrm{CO}, \mathrm{CO}_{2}$, $\mathrm{COCl}_{2}, \mathrm{COF}_{2}$, and small amounts of unidentified perhalocarbons.

Consideration of the ratios of tungsten reacted to $\mathrm{C}$ and to $\mathrm{CO}$ produced, in addition to the ratio, near 4, for the amount of halide ions to tungsten ions in the products, indicates that the main reaction may be represented by the equation, $2 \mathrm{WO}_{2}+2 \mathrm{CF}_{2} \mathrm{Cl}_{2}=\mathrm{WOF}_{4}+\mathrm{WOCl}_{4}+2 \mathrm{CO}$. The production of $\mathrm{CO}_{2}$ and of $\mathrm{WF}_{6}$ and $\mathrm{WCl}_{6}$ as well as $\mathrm{COCl}_{2}$ and $\mathrm{COF}_{2}$ can come about either through competing primary reactions or through secondary reactions. For instance, the decomposition of $\mathrm{CO}$ according to the equation $2 \mathrm{CO}=\mathrm{C}+\mathrm{CO}_{2}$, the formation of $\mathrm{COCl}_{2}$ from reaction of $\mathrm{CO}+\mathrm{Cl}_{2}=\mathrm{COCl}_{2}$, the chlorine coming from cracking of the $\mathrm{CF}_{2} \mathrm{Cl}_{2}$ molecule, or the reactions $\mathrm{COCl}_{2}+\mathrm{WOCl}_{4}=\mathrm{WCl}_{6}+\mathrm{CO}_{2}$ and $\mathrm{COF}_{2}+\mathrm{WOF}_{4}=\mathrm{WF}_{6}+\mathrm{CO}_{2}$ are all possible under the existing conditions of temperature and surfaces.

The distorted rutile structure of $\mathrm{WO}_{2}$ is such that on one crystal face it seems possible to adsorb four molecules of $\mathrm{CF}_{2} \mathrm{Cl}_{2}$ around each bonded pair of tungsten atoms. The distance between the bonded tungsten atoms is $2.48 \mathrm{~A}$ whereas the $\mathrm{F}-\mathrm{Cl}$ distance in freon is $2.53 \mathrm{~A}$. The formation of a complex resulting from the adsorption of four $\mathrm{CF}_{2} \mathrm{Cl}_{2}$ tetrahedral faces around each bonded pair on the plane of the $\mathrm{WO}_{2}$ crystal which contains the bonded pair of tungsten atoms is proposed as the first step in the $\mathrm{WO}_{2}-\mathrm{CF}_{2} \mathrm{Cl}_{2}$ reaction. Subsequent decomposition of the complex is mainly to give $\mathrm{CO}$, WOF $_{4}$ and WOCl $_{4}$, but decomposition along other paths to produce the other substances found by analysis, is not reasonable.

It is found that the reaction between $\mathrm{CCl}_{4}$ and $\mathrm{WO}_{2}$ at $350^{\circ} \mathrm{C}$ results in the production of $\mathrm{WOCl}_{4}$, $\mathrm{C}$, and $\mathrm{CO}$, while there is no reaction between $\mathrm{CF}_{4}$ and $\mathrm{WO}_{2}$ at any temperature up to and including $700^{\circ} \mathrm{C}$. 


\section{REFERENCES}

1. Michael, A. and A. Murphy, American Chem. Jour. 44:382 (1910).

2. Booth, H. S., W. Krasney-Ergen, and R. E. Heath, Jour. Amer. Chem. Soc. 68:1969 (1946).

3. Landau, R. and R. Rosen, Ind. Eng. Chem. 39:281 (1947).

4. Grimaldi and Davidson, U. S. Geol. Sur. Bul. No. 950:135-8 (1946).

5. Willard, H. H. and O. B. Winter, Ind. Eng. Chem., Anal Ed. 5:7 (1933). Churchill, H. V., Ibid., 17:720 (1945).

Huckabay, W. B., E. T. Welch, and A. V. Metler, Ibid., 19:154 (1947).

Hoskins, W. M. and C. A. Ferris, Ibid., 8:6 (1936).

Armstrong, W. D., Jour. Amer. Chem. Soc. 55:1741 (1933).

6. Kimball, R. H. and L. E. Tufts, Ind. Eng. Chem., Anal. Ed. 19:153 (1947).

7. Ruff, O., F. Eisner, and W. Heller, Zeit. anorg. Chem. $52: 256$ (1907).

8. Sears, G. W. and F. Lohse, Jour. Amer. Chem. Soc. 57:794 (1935).

9. Latimer, W. M. and J. H. Hildebrand, Reference Book of Inorganic Chemistry, Revised Ed., p 268, Macmillan, New York.

10. Latimer, W. M. and J. H. Hildebrand, Bbid., p 228.

11. Magneli, A., Ark. Kem Mineral. Geol., 12A, Nr. 4 (1935).

12. Pauling, L., Chem. Eng. News 25:2971 (1947).

13. Brockway, L. O., J. Phys. Chem. 41:185 (1937).

14. U. S. Patent $1,652,646$ (1927) to William B. Stoddard. British Patent 134,891 (1919) to O. J. Stannard. Wasmuht, R., Z. angew. Chem. 43:98 and 125 (1930).

15. Lindner, K., Zeit. anorg. Chem. 140:357 (1924); Ibid., 160:57 (1927). Lindner, K., Ibid., 162:203 (1927).

16. German Patent 266:973 (1910) to P. Jannasch. 